\title{
Implantes de hidroxiapatita em falhas ósseas produzidas no fêmur de ratos submetidos ao tabagismo passivo*
}

\author{
Hydroxyapatite implants in bone defects produced in \\ rat femurs submitted to passive tobacco exposure
}

\author{
Thiago Cerizza Pinheiro ${ }^{1}$, Felipe Faganelli Caboclo dos Santos², \\ Henrique Yassuhiro Shirane ${ }^{3}$, Marcelo Rodrigues da CunHA ${ }^{4}$
}

\section{RESUMO}

Introdução: Defeitos com perdas de massa óssea são freqüentemente tratados com enxertos ósseos autógenos. Implantes de biomateriais, como hidroxiapatita (HA), também têm sido utilizados com a mesma finalidade, substituindo os enxertos autógenos. Contudo, as condições de saúde do tecido ósseo são fundamentais para que haja a osteointegração do implante. Assim, o consumo excessivo de tabaco, de forma ativa ou passiva, pode prejudicar o processo de neoformação óssea frente ao implan-

* O presente trabalho foi desenvolvido junto ao Departamento de Morfologia e Patologia Básica da Faculdade de Medicina de Jundiaí e apoiado pelo Conselho Nacional de Desenvolvimento Científico e Tecnológico - CNPq que se estendeu de junho de 2007 a julho de 2008, sendo premiado pelo mesmo.

1. Acadêmico de Medicina do 3o ano da Faculdade de Medicina de Jundiaí (SP), Brasil.

2. Acadêmico de Medicina do 3o ano da Faculdade de Medicina de Jundiaí (SP), Brasil.

3. Acadêmico de Medicina do $2^{\circ}$ ano da Faculdade de Medicina de Jundiaí (SP), Brasil.

4. Doutor, Professor Adjunto do Departamento de Morfologia e Patologia Básica na Disciplina de Anatomia de Faculdade de Medicina de Jundiaí (SP), Brasil.

Endereço para correspondência: Anita Garibaldi, 39, apto. 101, Vila Isabel Éber - 13202-281 - Jundiaí (SP), Brasil. Tel.: (11) 76624349.

E-mail: tcp_ata@yahoo.com.br

Recebido em 17/10/08. Aprovado para publicação em 30/10/08. Copyright RBO2008 te de hidroxiapatita, devido a seus efeitos deletérios sobre o tecido ósseo. Objetivo: Avaliar as condições nutricionais dos animais e o processo de neoformação óssea quando grânulos de hidroxiapatita porosa são implantados em falhas ósseas no fêmur de ratos submetidos ao tabagismo passivo. Métodos: Foram implantados grânulos de hidroxiapatita porosa em defeitos ósseos produzidos na epífise distal do fêmur esquerdo de ratos sujeitos ao tabagismo passivo prolongado. Os animais foram acompanhados ao longo do tratamento do tabagismo com duração de seis meses avaliando suas condições físicas. Após oito semanas do implante ósseo do biomaterial, os animais foram sacrificados e as amostras da área do implante submetidas aos métodos histológicos de rotina e mantidas em blocos de parafina para análise histológica, morfométrica, e radiológica. Resultados: Identificou-se que a variação de massa do grupo experimental foi mais intensa quando comparada com a do grupo controle. Quanto aos achados radiológicos, observou-se aparente imagem mais radiolúcida e organizada no grupo controle. Na análise morfológica, houve melhor fechamento do defeito ósseo bem como a osteointegração da hidroxiapatita no grupo controle. Ao comparar o volume de osso formado na área receptora do fêmur, entre o grupo controle e experimental, notou-se que os valores encontrados para os animais submetidos ao tabagismo passivo foram 
significativamente menores quando comparados com os do grupo controle. Conclusão: A neoformação óssea em defeitos do esqueleto pode ocorrer naturalmente em animais submetidos ao tabagismo passivo, no entanto, de forma mais lenta e em menor proporção.

Descritores - Hidroxiapatita; Falha óssea; Tabaco

\section{ABSTRACT}

Introduction: Defects with bone mass loss are frequently treated with bone autografts. Endografts of bones using biomaterials, such as hydroxyapatite (HA) also have been used for the same purpose, replacing autografts. However, bone tissue health conditions are basic for osteointegration of the implant. Thus, excessive tobacco consumption, either as an active or as a passive smoker, may harm the process of bone neoformation with a hydroxyapatite implant due to its deleterious effects to bone tissue. Objective: To evaluate the nutritional status of the animals and the process of bone neoformation when porous hydroxyapatite granules are implanted in bone defects of the femur of rats submitted to passive tobacco exposure. Method: Porous hydroxyapatite granules were implanted in bone defects produced in the left distal femoral epiphysis of rats subjected to prolonged passive tobacco exposure. The animals were followed along the treatment of tobacco exposure during six months, to evaluate their physical conditions. After eight weeks of the bone implant with the biomaterial, the animals were sacrificed and the specimens of the implant region were submitted to routine histological testing, and maintained in paraffin blocks for morphometric histological and radiological analysis. Results: The mass variation of the experimental group was found to be more intense than that of the control group. As to radiological findings, the control group had an apparent more radio lucent and organized image. In the morphological analysis, there was a better closing of the bone defect and osteointegration of hydroxyapatite in the control group. Upon comparing the volume of bone formed in the receiving area of the femur between the control and the experimental group, the values found for the animals submitted to passive tobacco exposure was lower than that found for the control group. Conclusion: Bone neoformation in skeletal defects can occur naturally in animals submitted to passive tobacco exposure, but in a slower manner and in lower proportion.

Keywords - Hydroxyapatite; Bone defect; Tobacco

\section{INTRODUÇÃO}

Defeitos com perda de massa óssea resultante de fraturas patológicas ou traumáticas, desenvolvimento anormal do esqueleto ou ressecção de tumores, freqüentemente são reparados com enxertos ósseos autógenos. No entanto, apresentam algumas desvantagens, como morbidade da área doadora, reabsorção pós-operatória, contornos irregulares dos enxertos angulares e complicações como dor crônica e lesões vasculares durante o procedimento cirúrgico ${ }^{(1-2)}$.

Diante das limitações da utilização dos enxertos ósseos autógenos, alguns materiais biocompatíveis vêm sendo pesquisados para substituí-los na aplicação clínica. Para esse propósito, o material, primeiramente, deve responder a determinados requisitos, como estrutura estável, rapidez na incorporação com o tecido ósseo, promover osteocondução e gerar pouca ou nenhuma complicação associada a seu uso ${ }^{(3)}$. Atendendo a essas exigências, o fosfato de cálcio, um biomaterial cerâmico comercializado desde 1970 na forma de hidroxiapatita e tricálcio fosfato, tem recebido considerável atenção no campo da cirurgia plástica, ortopédica e odontológica ${ }^{(4-6)}$.

A hidroxiapatita $\left(\mathrm{Ca}_{5}\left(\mathrm{PO}_{4}\right) \mathrm{OH}\right)$ é fabricada para uso clínico na forma de blocos ou grânulos, porosa ou den$\mathrm{sa}^{(7)}$. Pesquisadores criticam a implantação do tipo denso, pela impossibilidade de promover crescimento ósseo para seu interiore, na forma de blocos, devido à dificuldade de ser modelada e pela fragilidade quando submetida a carga mecânica ${ }^{(8-9)}$. Grânulos porosos são estudados em experimentos e clinicamente, por ser bem tolerados pelo tecido ósseo, além de facilitar a infiltração de osteoblastos e proliferação de vasos sanguíneos essenciais ao processo regenerativo ${ }^{(8,10)}$. A hidro- 
xiapatita em forma de grânulos facilita a adaptação ao contorno dos defeitos ósseos, é quimicamente estável, não tem restrição quanto à quantidade disponível e não está sujeita à rejeição imunológica ${ }^{(11-13)}$.

Rosen et al estudaram as propriedades biológicas da hidroxiapatita quando implantada em regiões do esqueleto maxilofacial osteotomizado. Foram avaliados 11 pacientes e, após 10 meses da operação, foi feito o estudo das biópsias. Os autores verificaram a ausência de infecção, rápido crescimento fibrovascular e de osso neoformado nos espaços entre os blocos das cerâmicas, indicando que a hidroxiapatita é boa alternativa a ser utilizada nas cirurgias reparadoras do esqueleto facial ${ }^{(14)}$.

Uchida et al relataram 60 casos de pacientes com tumores ósseos tratados por ressecção cirúrgica, seguida de implantação de hidroxiapatita nas falhas provocadas pela cirurgia. Após 36 meses da operação, observaram que em nenhum paciente houve recidiva do tumor e que não ocorreram complicações na área receptora. Por meio de análises radiográficas e histológicas de biópsias, notaram formação óssea ao redor da hidroxiapatita, fechando totalmente a falha óssea. Além disso, houve crescimento ósseo entre os grânulos da cerâmica, tornando este biomaterial opção viável nos tratamentos de defeitos provocados pela retirada de tumores ósseos benignos ${ }^{(15)}$.

Com a contribuição positiva nos reparos de defeitos ósseos, a hidroxiapatita vem recebendo atenção especial na busca de materiais substitutos para os enxertos autógenos. Duarte et al analisando o processo de osteointegração de hidroxiapatita sintética em defeito no processo alveolar da mandíbula de cães, observaram intensa proliferação de osteoblastos e neovascularização na presença do implante. A biocompatibilidade da hidroxiapatita permitiu a integração com o processo alveolar por meio da formação direta de osso lamelar e a ocorrência de neoformação óssea à medida que a hidroxiapatita era degradada ${ }^{(16)}$.

Vital et al avaliaram os compósitos de hidroxiapatita sintética com carbono (HAC) e a hidroxiapatita sintética com carbono e fosfato biácido de sódio (HACF), ambos na forma sólida, como substituto ósseo em de- feitos na ulna de 36 coelhos adultos. O uso de HAC e HACF na ulna de coelho mostrou-se método eficiente, pois não apresentou sinais de infecção e nem evidência de rejeição, demonstrando a biocompatibilidade do material ${ }^{(17)}$.

Quanto às indicações do implante de hidroxiapatita, esta prática direciona-se para as correções de defeitos craniomaxilofaciais, traumatismos, deformidades congênitas, podendo inclusive ser utilizado na medicina estética $^{(18-19)}$. Porém, apesar de sua aplicabilidade viável, existem algumas contra-indicações que podem comprometer os resultados esperados, como o consumo exagerado de tabaco, álcool e outras drogas, devido a seus efeitos deletérios sobre tecido ósseo ${ }^{(20)}$.

O cigarro tem elevada quantidade de agentes oxidantes que promovem efeitos deletérios nos órgãos. No tecido ósseo provoca quadro de osteoporose, tornando o osso predisposto a possíveis fraturas patológicas, além de dificultar ou retardar o metabolismo ósseo, principalmente quando há um processo de reparo, como nos casos da consolidação de fraturas ou defeitos ósseos ${ }^{(21)}$.

Para Saldanha et al, a ação da nicotina sobre a regeneração óssea de defeitos criados cirurgicamente em rebordos alveolares nas mandíbulas de cães demonstrou que a administração de nicotina crônica influenciou significativamente na baixa densidade do tecido ósseo neoformado, tornando-o mais frágil ${ }^{(22)}$.

O reparo do osso é um processo que envolve a estabilização dos fragmentos, consolidação por união óssea, revascularização das extremidades dos fragmentos necrosados e, finalmente, remodelagem interna e externa do tecido neoformado. Além disso, pode haver a necessidade do uso de hidroxiapatita nos casos em que há perda acentuada de massa óssea em traumatismos. No entanto, este processo pode ficar comprometido quando o tecido ósseo está submetido a fatores desfavoráveis, como no caso dos agentes psicoativos do tabagismo.

O presente trabalho teve por objetivo avaliar as condições nutricionais dos animais frente ao tabagismo passivo e o processo de neoformação óssea quando grânulos de hidroxiapatita porosa são implantados em 
falhas ósseas no fêmur de ratos submetidos ao tabagismo passivo e de ratos-controle para efeito comparativo.

\section{MÉTODOS}

Foram utilizados 10 ratos albinos (Rattus norvegicus) Wistar adultos, machos, com 12 semanas de idade, com aproximadamente $400 \mathrm{~g}$ de massa corporal, fornecidos pelo Biotério da Faculdade de Medicina de Jundiaí. Os animais foram divididos em dois grupos com cinco animais cada. O grupo experimental foi submetido ao tabagismo passivo durante seis meses. O grupo controle recebeu igual tratamento, exceto a exposição ao tabaco.

Tratamento com tabaco - O grupo experimental foi mantido em uma cuba de acrílico (figura 1) equipada com um cooler, para que houvesse distribuição por igual de fumaça em todas as subunidades onde os ratos foram isolados individualmente. $\mathrm{O}$ grupo recebeu inicialmente quantidades crescentes de cigarros até estagnar em cinco cigarros/dia durante seis meses. Ambos os grupos - experimental e controle - receberam a mesma dieta sólida (ração Purina ${ }^{\circledR}$ na forma de grãos) e líquida (água ad libitum).

Durante todo o experimento, foram realizadas observações diárias dos animais a fim de detectar qual-

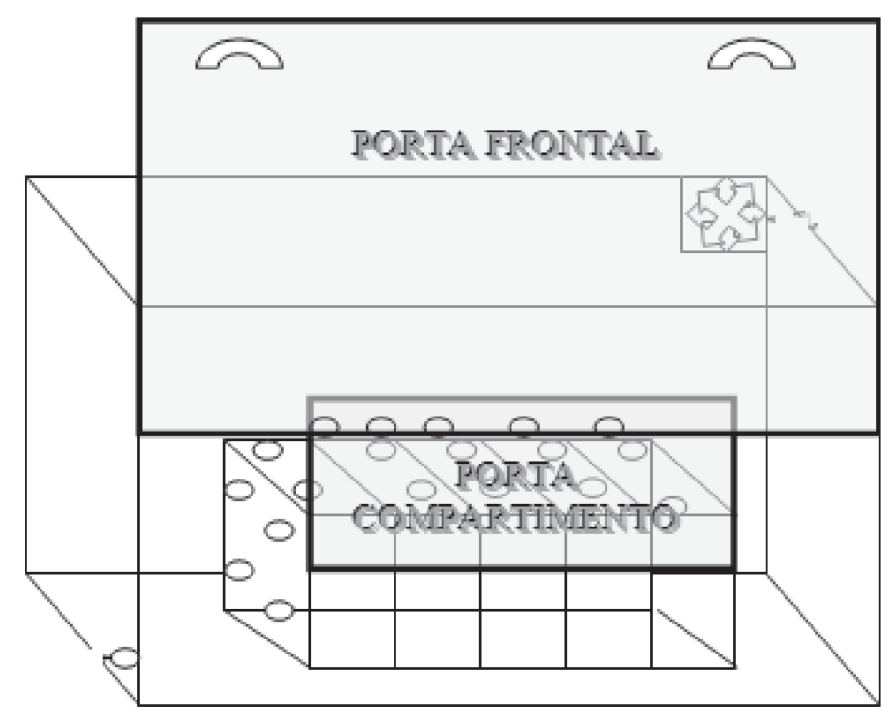

Figura 1 - Cuba de acrílico

Cortesia de Carvalho CAF.

Rev Bras Ortop. 2008;43(10):433-4 quer modificação no comportamento, bem como alterações macroscópicas nos aspectos das fezes, urina e pêlos. Periodicamente, foi realizado controle da quantidade de ração e liquido ingerido por animal e do ganho de massa corporal, com o intuito de avaliar o estado nutricional dos mesmos frente ao tabagismo experimental.

Após o período de submissão ao tabagismo passivo experimental, os animais foram operados para implantação da hidroxiapatita.

Os animais foram pesados e anestesiados com solução de ketamina (Francotar) e cloridrato de xilazina (Virbaxyl $^{\circledR}$ a $2 \%$ ), na proporção de 1:1 e na dose de $0,10 \mathrm{ml} / 100$ gramas de massa corpórea por via intramuscular.

Os animais foram colocados em decúbito dorsal e realizada a tricotomia da região crural, seguida de incisão longitudinal mediana na pele do terço distal anterior da coxa. Esta foi afastada lateralmente para que fosse feita uma incisão longitudinal no músculo quadríceps femoral e expondo o periósteo, que foi seccionado transversalmente e separado da superfície óssea usando o levantador de periósteo. Em seguida, usando uma broca cirúrgica de $3,5 \mathrm{~mm}$ de diâmetro acoplada a um minimotor, foi feita uma falha óssea na epífise distal do fêmur que foi preenchida com grânulos de hidroxiapatita porosa $\left(\right.$ Genius $\left.^{\circledR}\right)$. Durante a cirurgia, foi feita raspagem do defeito ósseo com a extremidade do afastador de periósteo, na tentativa de não deixar nenhum resquício de fragmento ósseo, o qual poderia contribuir para o reparo do mesmo.

Estudo histológico - Os fêmures esquerdos foram descalcificados e tratados pelo fixador de medula Allki$m i a^{\circledR}$ durante 10 dias. Após a descalcificação, os ossos foram reduzidos, mantendo apenas a área receptora do implante. As amostras foram lavadas em água corrente over night, desidratadas em álcool etílico, diafanizadas em xilol e, finalmente, incluídas em parafina. Foram obtidos cortes transversais semi-seriados de $5 \mu \mathrm{m}$ e corados pela hematoxilina e eosina.

Estudo morfométrico - A análise quantitativa foi baseada no método de estereologia, o qual permite determinar parâmetros tridimensionais de um órgão, 
tecido ou estrutura morfológica por meio de contagem de pontos de imagens bidimensionais ${ }^{(23)}$. A quantificação do osso neoformado foi realizada de acordo com o princípio de Delesse, observando-se a fórmula $\mathrm{Vv}=\mathrm{Pp} / \mathrm{Pt}(\%)$, onde: $\mathrm{Vv}$ é a densidade de volume ou volume relativo; Pp é a quantidade de pontos (intersecção de linhas) sobre o osso neoformado; Pt é o número total de pontos do sistema. Por meio de um retículo quadrilátero produzido no computador com um sistema de 100 pontos eqüidistantes, calculou-se a densidade de volume ósseo neoformado nos locais do implante de hidroxiapatita.

Estudo estatístico - A partir dos valores obtidos da morfometria dos animais, tanto do grupo controle como do experimental, foram calculados médias e desvios padrões para cada um deles. Obteve-se um percentual da osteointegração da hidroxiapatita para cada rato e depois a média para os grupos. De posse desses valores, aplicou-se o teste $t$ de Student para a comparação entre as situações (controle x experimental) e o teste de comparação paramétrica e não paramétrica ${ }^{(24)}$.

\section{RESULTADOS}

\section{I - Avaliação nutricional}

Consumo de ração e líquido - No gráfico 1 e na tabela 1, notamos que o consumo de sólidos aumentou progressivamente em ambos os grupos com exceção no período final do tratamento no grupo submetido ao tabagismo passivo.

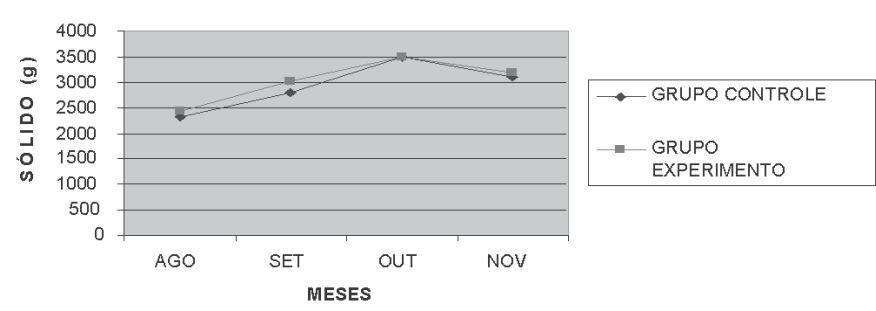

Gráfico 1 - Consumo de ração durante o experimento

Durante o referido período, notamos mínima variação no consumo de líquido em ambos os grupos (gráfico 2).

Peso corpóreo - Quanto à variação da massa corpórea, podemos observar que os dois grupos ganha- ram massa ao longo do experimento, principalmente o grupo controle. Vale ressaltar que no início do experimento houve queda de massa corpórea do grupo experimental que no decorrer dos meses se estabilizou (gráfico 3).

Na tabela 1, notamos que a variação de massa do grupo experimental foi mais intensa quando comparada com a do grupo controle.

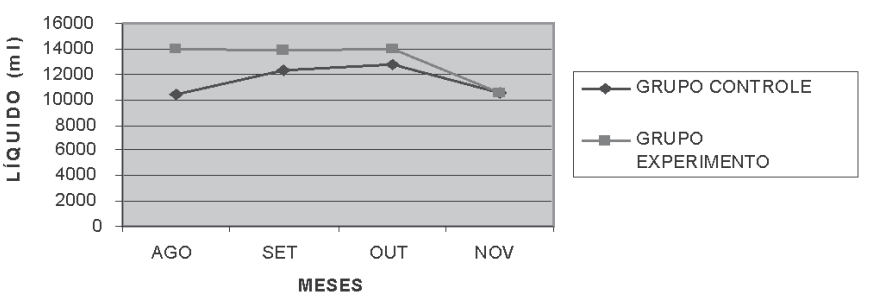

Gráfico 2 - Consumo de líquido durante o experimento

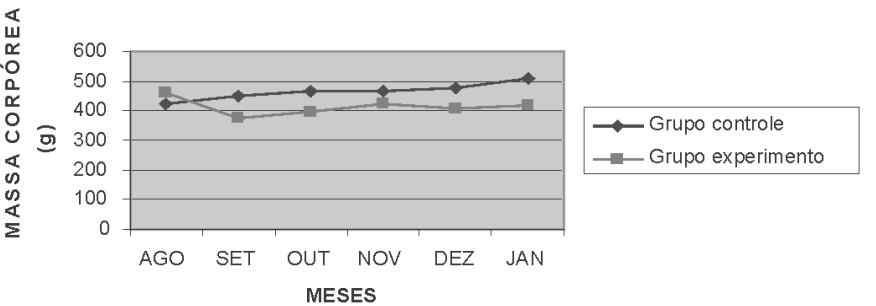

Gráfico 3 - Média das massas corpóreas dos ratos/mês

TABELA 1

Média e desvio padrão de variação de peso (peso final - peso inicial) e consumos líquidos e sólidos (por mês) segundo comparação entre grupos

\begin{tabular}{lccc}
\hline \multicolumn{1}{c}{ Grupo } & $\begin{array}{c}\text { Variação da } \\
\text { massa }(\mathbf{g})\end{array}$ & $\begin{array}{c}\text { Consumo } \\
\text { sólido }(\mathbf{g})\end{array}$ & $\begin{array}{c}\text { Consumo } \\
\text { líquido }(\mathrm{ml})\end{array}$ \\
\hline Controle & $96,4 \pm 40,7$ & $97,62 \pm 16,6$ & $383,20 \pm 40,77$ \\
Experimento & $68,4 \pm 41,4$ & $100,85 \pm 14,97$ & $264,08 \pm 20,04$ \\
\hline
\end{tabular}

II - Avaliação radiológica - Nos animais-controle notou-se aparente imagem mais radiolúcida e organizada na comparação com o grupo experimental. No grupo controle parece ter havido melhor fechamento do defeito ósseo bem como a osteointegração da hidroxiapatita.

III - Avaliação histológica - No grupo controle observou-se que a continuidade da margem da epífise 
distal do fêmur apresentou-se quase que totalmente uniforme e contínua na área do implante, embora em processo de remodelação. Notou-se também que a falha óssea foi consideravelmente preenchida por osso neoformado de característica mais compacta devido à presença do osso maturo (figura 2).

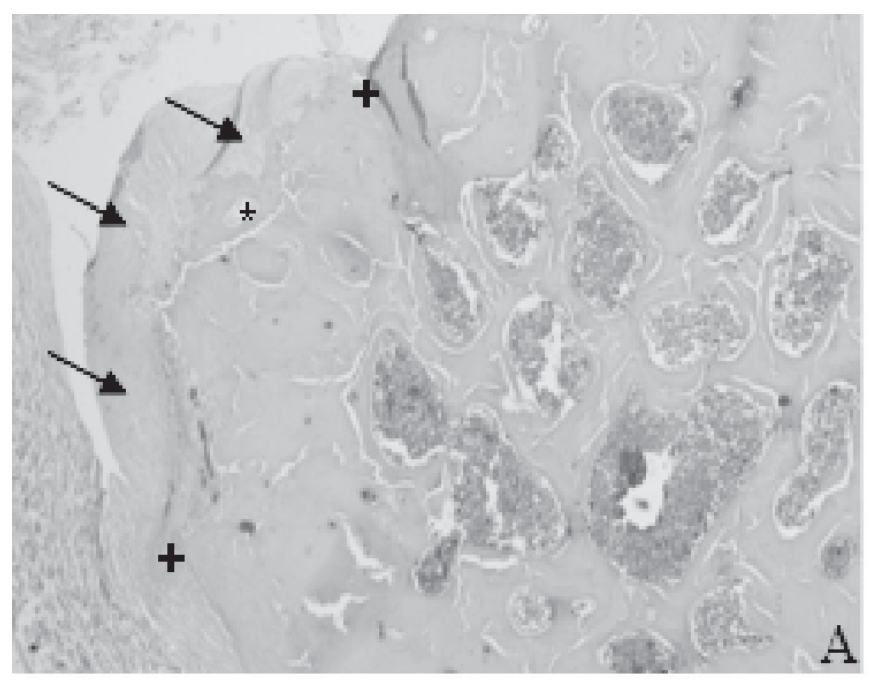

Figura 2 - Fêmur de rato controle. Observa-se pequena falta de fechamento do defeito ósseo (*) e a presença de tecido ósseo neoformado ao redor do implante (setas). Observa-se a presença de osso neoformado nas margens do defeito ósseo (+). (HE 10x).

No grupo experimental notou-se descontinuidade da margem óssea da área receptora devido à persistência de considerável parte da falha óssea provocada, sendo esta preenchida por tecido conjuntivo e osso neoformado com disposição trabeculada. Além disso, houve neoformação óssea a partir das bordas do defeito ósseo com aspecto de osso imaturo, devido à presença de osteócitos jovens no interior de lacunas desorganizadas (figura 3).

IV - Avaliação morfométrica - Ao comparar o volume de osso formado na área receptora do fêmur entre o grupo controle e o experimental, notou-se que os valores encontrados para os animais submetidos ao tabagismo passivo $(8,92 \%)$ foram menores quando comparados com os do grupo controle $(69,8 \%)$, havendo diferença estatística significativamente $(p<0,05)$ (tabela 2).

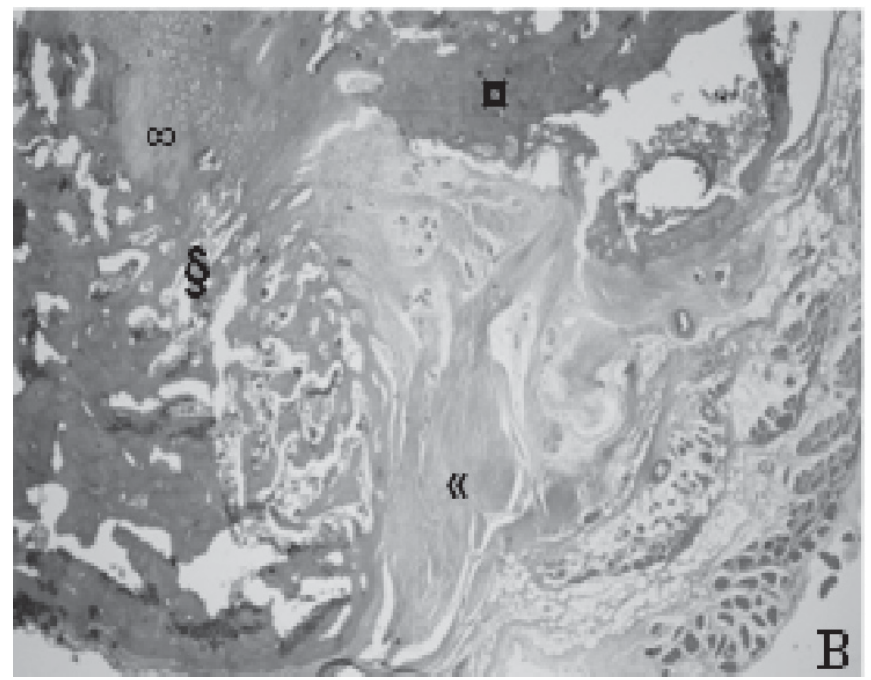

Figura 3 - Fêmur de rato submetido ao tabagismo passivo. Observa-se menor osteointegração com presença de numerosos osteócitos $(\infty)$ dispostos na matriz óssea (\$) de forma desordenada. A falha óssea pode ser visualizada de modo mais nítido, sendo possível notar uma distância da área do implante («) com o tecido formado ( $)$, demonstrando a persistência de parte do defeito ósseo provocado. (HE - 10x).

TABELA 2

Média e desvio padrão dos achados morfométricos em ambos os grupos

\begin{tabular}{lcc}
\hline & Controle & Experimento \\
\hline $\begin{array}{l}\text { Média e } \\
\text { desvio-padrão }\end{array}$ & $0,698 \pm 0,016^{*}$ & $0,08925 \pm 0,028786933^{*}$
\end{tabular}

Resultado estatístico: 0,000000039

* SD e média

\section{DISCUSSÃO}

Questões referentes a algumas doenças humanas podem ser favoravelmente estudadas em animais de laboratório, inclusive aquelas decorrentes do uso abusivo de tabaco, tais como alterações do tecido ósseo ${ }^{(25)}$.

Há forte questionamento se as alterações ósseas dos animais tratados com tabaco decorrem do efeito direto do tabaco ou seriam consequiência da deficiência nutricional. Diante desse fato torna-se obrigatório e essencial o monitoramento do estado de saúde de cada animal durante os experimentos com tabaco. A variação da quantidade de ração e água consumida pode modificar respostas biológicas em muitos dos experimentos sobre tabagismo ${ }^{(26)}$. 
Neste trabalho, atentou-se para o devido cuidado em acompanhar periodicamente o estado de saúde dos animais por meio do controle da quantidade de ração e líquido consumidos. Ao longo do experimento, notou-se que houve aumento progressivo do consumo de sólidos em ambos os grupos, com exceção do período final do tratamento com tabagismo passivo. Para Carvalho et al, o consumo de ração dos ratos submetidos à nicotina foi maior quando comparado com a do grupo controle ${ }^{(27)}$.

Quanto ao consumo líquido, observamos mínima variação em ambos os grupos, achado em acordo com o estudo de Carvalho et al em que o consumo de água foi praticamente o mesmo para o grupo controle e experimental, não sendo notada diferença significativa ${ }^{(27)}$.

Outra preocupação, quanto ao estado nutricional dos animais, foi acompanhar a variação do peso corpóreo de cada um deles, pois a desnutrição protéica em roedores é caracterizada principalmente pela perda de massa corpórea ${ }^{(28)}$. Quanto à variação da massa corpórea, houve aumento de massa ao longo de nosso experimento, principalmente no grupo controle. Booze et al notaram que administrações moderadas $(50 \mu \mathrm{k} / \mathrm{kg} /$ dia) de nicotina por um período de 14 dias não demonstraram diferenças significativas de massa corpórea entre ratos controle e experimentais ${ }^{(29)}$. Já Faraday et al observaram que administração de $12 \mathrm{mg}$ de nicotina $/ \mathrm{kg} /$ dia durante 21 dias reduziu de maneira significativa a massa corpórea dos ratos experimentais ${ }^{(30)}$.

O tratamento com implantes osteointegrados é método altamente eficiente, apresentando resultados previsíveis em grande número de pacientes. Entretanto, casos de falhas de implantes têm sido publicados e as causas de tais falhas têm sido motivo de especulação. Qualidade e quantidade óssea pobres, implantes curtos, tabagismo, trauma cirúrgico e contaminação são fatores associados à falha do implante ${ }^{(31)}$.

Além das graves alterações que o tabagismo provoca diretamente no tecido ósseo, estudos como de Albrektsson et al têm sugerido que o tabaco também pode interferir no processo de osteointegração dos implantes de biomateriais, inviabilizando, às vezes, sua utilização ${ }^{(32)}$.
Sanzana constatou, por meio de dados radiológicos, que todos os implantes de hidroxiapatita feitos em coelhos submetidos a um mesmo procedimento cirúrgico, e com hábitos saudáveis, se osteointegraram ${ }^{(33)}$. Segundo Balatsouka, a exposição à nicotina por curto período de tempo (aproximadamente quatro semanas) não alterou de maneira significativa a osteointegração e a cicatrização de tíbias de coelhos submetidas ao defeito ósseo( ${ }^{(34)}$.

Saldanha et al avaliaram histometricamente a influência da nicotina sobre a regeneração óssea de defeitos criados cirurgicamente em rebordos alveolares dentários de cães. Constataram que a administração de nicotina influenciou significativamente a densidade do tecido ósseo neoformado, concluindo que a nicotina pode afetar, mas não impedir, a regeneração de defeitos ósseos ${ }^{(22)}$.

Neste trabalho, identificamos que a osteointegração da hidroxiapatita porosa pode ser esperada mesmo quando implantada em animais submetidos ao tabagismo passivo, apesar do atraso considerável na evolução do processo de neoformação óssea e do menor volume de osso formado.

\section{CONCLUSÕES}

Não houve diferença significativa quanto à avaliação da evolução nutricional entre os grupos analisados;

A quantidade de osso formado nas áreas receptoras dos animais controle foi maior que a encontrada nas respectivas áreas do grupo experimental;

A osteointegração de hidroxiapatita pode ser esperada quando implantada em animais sob ação de tabagismo passivo;

O volume ósseo formado foi superior no grupo controle, o que demonstra a superioridade osteogênica nos animais livres dos efeitos adversos do tabagismo.

\section{REFERÊNCIAS}

1. Mark DE, Hollinger JO, Hastings C Jr, Chen G, Marden LJ, Reddi AH. Repair of calvarial nonunions by osteogenin, a bone-inductive protein. Plast Reconstr Surg. 1990;86(4):62330.

2. Younger EM, Chapman MW. Morbidity at bone graft donor sites. J Orthop Trauma. 1989;3(3):192-5. 
3. Mellonig JT. Porous particulate hydroxyapatite in a human periodontal osseous defect: a case report. Int J Periodontics Restorative Dent. 1991;11(3):217-23.

4. Costantino PD, Friedman CD, Jones K, Chow LC, Sisson GA. Experimental hydroxyapatite cement cranioplasty. Plast Reconstr Surg. 1992;90(2):174-85.

5. Oonishi H. Orthopaedic applications of hydroxyapatite. Biomaterials. 1991;12(2):171-8.

6. Ono I, Ohura T, Murata M, Yamaguchi H, Ohnuma Y, Kuboki Y. A study on bone induction in hydroxyapatite combined with bone morphogenetic protein. Plast Reconstr Surg. 1992;90(5): 870-9.

7. Hönig JF, Merten HA, Wiltfang J. Significance of the periosteum in onlay craniofacial augmentation. J Craniofac Surg. 1998;9(3):260-6.

8. Guirro RR. O uso da hidroxiapatita associado a estimulação ultra sônica pulsada de baixa intensidade na correção de falha óssea. Estudo experimental em coelhos [dissertação]. São Carlos: Escola de Engenharia de São Carlos da Universidade de São Paulo; 1995.

9. Burstein FD, Cohen SR, Hudgins R, Boydston W. The use of porous granular hydroxyapatite in secondary orbitocranial reconstruction. Plast Reconstr Surg. 1997 Sep;100(4):869-74.

10. Thomson RC, Yaszemski MJ, Powers JM, Mikos AG. Hydroxyapatite fiber reinforced poly(alpha-hydroxy ester) foams for bone regeneration. Biomaterials. 1998;19(21):193543.

11. Hönig JF, Merten HA. Subperiosteal versus epiperiosteal forehead augmentation with hydroxylapatite for aesthetic facial contouring: experimental animal investigation and clinical application. Aesthetic Plast Surg. 1993;17(2):93-8.

12. Ono I, Gunji H, Kaneko F, Numazawa S, Kodama N, Yoza S. Treatment of extensive cranial bone defects using computerdesigned hydroxyapatite ceramics and periosteal flaps. Plast Reconstr Surg. 1993;92(5):819-30.

13. Okazaki A, Koshino T, Saito T, Takagi T. Osseous tissue reaction around hydroxyapatite block implanted into proximal metaphysis of tibia of rat with collagen-induced arthritis. Biomaterials. 2000;21(5):483-7.

14. Rosen HM, McFarland MM. The biologic behavior of hydroxyapatite implanted into the maxillofacial skeleton. Plast Reconstr Surg. 1990;85(5):718-23.

15. Uchida A, Araki N, Shinto Y, Yoshikawa H, Kurisaki E, Ono K. The use of calcium hydroxyapatite ceramic in bone tumour surgery. J Bone Joint Surg Br. 1990;72(2):298-302.

16. Duarte TS, Borges AP, Lavor MS, Figueiras R, Tsiomis AC, Oliveira FL, et al. Osteointegração da hidroxiapatita sintética no processo alveolar da mandíbula de cães: aspectos histológicos. Arq Bras Med Vet Zootec. 2006;58(5):849-53.
17. Vital CC, Borges AP, Fonseca CC, Tsiomis AC, Carvalho TB, Fontes EB, et al. Biocompatibilidade e comportamento de compósitos de hidroxiapatita em falha óssea na ulna de coelhos. Arq Bras Med Vet Zootec. 2006;58(2):175-83.

18. Golec TS, Krauser JT. Long-term retrospective studies on hydroxyapatite coated endosteal and subperiosteal implants. Dent Clin North Am. 1992;36(1):39-65.

19. Hebert S, Xavier R. Ortopedia e traumatologia: princípios e prática. 3a ed. Porto Alegre: Sarvier; 2003.

20. Stobaugh RK. Status of the hydroxyapatite-coated unilateral subperiosteal implant using direct bone impressions. Dent Clin North Am. 1992;36(1):67-76.

21. Hoffmann D, Wynder EL. Chemical constituents and bioactivity of tobacco smoke. IARC Sci Publ. 1986;(74):14565.

22. Saldanha JB, Pimentel SP, Casati MZ, Sallum AW, Sallum EA, Nociti FH. Histologic evaluation of the effect of nicotine administration on bone regeneration. A study in dogs. Braz Oral Res. 2004;18(4):345-9.

23. Mandarim-de-Lacerda CA. What is the interest of normal and pathological morphological research to be quantitative? The exemple of the stereology. Braz J Morphol Sci. 1999;16(2): $131-9$.

24. Montgomery DC. Design and analysis of experiments. 3rd ed. New York: John Wiley; 1991.

25. Lorenz R, Jänicke-Lorenz J. Electron microscopic observation on osteocytes of chronically alcoholized rats. Arch Orthop Trauma Surg. 1983;102(2):118-22.

26. Weisbroth SH, Paganelli RG, Salvia M. Evaluation of a disposable water system during shipment of laboratory rats and mice. Lab Anim Sci. 1977;27(2):186-94.

27. Carvalho CA, Favaro WJ, Padovani CR, Cagnon VH. Morphometric and ultrastructure features of the ventral prostate of rats (Rattus norvegicus) submitted to long-term nicotine treatment. Andrologia. 2006;38(4):142-51.

28. Sampson HW, Perks N, Champney TH, DeFee B 2nd. Alcohol consumption inhibits bone growth and development in young actively growing rats. Alcohol Clin Exp Res. 1996;20(8):137584.

29. Booze RM, Welch MA, Wood ML, Billings KA, Apple SR, Mactutus CF. Behavioral sensitization following repeated intravenous nicotine administration: gender differences and gonadal hormones. Pharmacol Biochem Behav. 1999;64(4): 827-39.

30. Faraday MM, Elliott BM, Grunberg NE. Adult vs. adolescent rats differ in biobehavioral responses to chronic nicotine administration. Pharmacol Biochem Behav. 2001;70(4):47589. 
31. Cury PR, Sendyk WR, Sallum AW. Etiologia da falha de implantes osseointegrados. Ver Bras Odontol. 2003; 60(3):1925 .

32. Albrektsson T, Brånemark PI, Hansson HA, Lindström J. Osseointegrated titanium implants. Requirements for ensuring a long-lasting, direct bone-to-implant anchorage in man. Acta Orthop Scand. 1981;52(2):155-70.
33. Sanzana E. Evaluation of a phosphocalcic cement as bone substitute in vivo in rabbits. Rev Chil Cir. 2006;58(6):431-40.

34. Balatsouka D, Gotfredsen K, Lindh CH, Berglundh T. The impact of nicotine on osseointegration. An experimental study in the femur and tibia of rabbits. Clin Oral Implants Res. 2005; 16(4):389-95. 